\title{
СОЗДАНИЕ И ИСПОЛЬЗОВАНИЕ ДИДАКТИЧЕСКИХ КОМПЬЮТЕРНЫХ ИГР В ПРОЦЕССЕ ОБУЧЕНИЯ ФИЗИКЕ
}

\section{CREATION AND USE OF DIDACTIC COMPUTER GAMES IN THE PROCESS OF TEACHING PHYSICS}

\author{
E. Fadeeva \\ R. Mingazov \\ A. Muzafarov \\ L. Tukhvatullina
}

Summary: For successful adaptation to the modern world, it is necessary to use modern methods and means. The curriculum of the school physics course is no exception. Currently, a huge number of computer programs, virtual laboratories and games have been created that allow students to master complex and difficult material in a visual, playful and exciting way. This article will reveal the concept of didactic computer games, their significance, and give many examples of existing games along with options for their use.

Keywords: physics, computer games, programs, physical laws, problems, competition, efficiency.

\author{
Фадеева Елена Юрьевна \\ ассистент, Казанский (Приволжский) федеральный \\ университет \\ Lenoktggpy@mail.ru
}

Мингазов Рамиль Хаернасович Д.п.н., профессор, Казанский (Приволжский) федеральный университет

Музафаров Азат Фаритович

К.э.н., доцент, Казанский государственный архитектурно-строительный университет

Тухватуллина Лилия Азатовна эксперт, директор, ООО «Инженерный цент»

Аннотация: Для успешной адаптации к современному миру необходимо использовать современные методы и средства. Не является исключением и программа обучения школьного курса физики. В настоящее время создано огромное количество компьютерных программ, виртуальных лабораторий и игр, которые позволяют учащимся осваивать сложный и тяжелый в восприятии материал наглядно, в игровой и увлекательной форме. В данной статье раскроется понятие дидактических компьютерных игр, их значимость, приведётся множество примеров существующих игр вместе с вариантами их использования.

Ключевые слова: физика, компьютерные игры, программы, физические законы, задачи, соревнование, эффективность.

важности изучаемых процессов.

Поэтому нужно совместить запросы детей, их увлечения со школьной программой и прийти к общему компромиссу между учителем и учащимся. Так как дети много времени проводят за компьютерами, играя в различные игры, изучение мира науки должно происходить тоже посредством компьютерных игр. Достаточно сложно представить, как преобразовался мир всего за несколько лет, но теперь любой предмет можно изучать с помощью игр, виртуальных лабораторий, компьютерных программ, ресурсов сети Интернет. Причем всё это сделано в интересной форме, где дети смогут не только получить новые знания, но и насладиться сопровождающими эффектами физических явлений. Во время всех этих процессов дети познают мир с научной точки зрения и действительно заинтересовываются в получении больших, дополнительных знаний.

Повышение эффективности обучения, формирование положительной мотивации к учению и умственной самостоятельности учащихся связано с применением дидактических игр, которые могут быть использованы как на уроках, так и во внеклассной работе по предмету. 
Применение дидактических игр позволяет решать следующие педагогические задачи:

- воспитание интереса к учению,

- развитие логического мышления учащихся,

- повышение эффективности обучения,

- облегчение процесса учения,

- улучшение психологического климата в коллективе.

При этом важно обеспечить выполнение ряда дидактических требований:

- игра должна вызывать у учащихся только положительные эмоции,

- игра должна основываться на свободном творчестве и самодеятельности учащихся,

- в игре обязателен элемент соревнования между командами или отдельными участниками,

- игра должна учитывать возрастные особенности учащихся.

Обучение в игре строится с учетом следующих принципов:

1. Принцип целесообразности предполагает четкое видение поставленной цели. Реализуется через построение учебного процесса соответственно заданной цели, поэтапное ее достижение в процессе учебной деятельности.

2. Принцип дифференциации учитывает дифференциацию учебного материала и знание учителем индивидуальных способностей учащихся класса. Реализуется на основе предварительной работы учителя по созданию дидактического материала для конкретного класса.

3. Принцип кооперации означает согласованность действий учащихся. Реализуется через комплектование групп по интересам, предоставление им выбора способа деятельности, коллективное взаимодействие при выполнении поставленной задачи.

4. Принцип актуальности предполагает воспитание у учащихся интереса к учению, так как в наше время интерес к знаниям падает. Реализуется через игровые навыки учащихся, которые развиты у них с детства.

Игровая деятельность осуществляется поэтапно:

1-й этап - подготовительный, предусматривает домашнюю работу учащихся по повторению материала.

2-й этап - выявление (выделение) учителем цели занятия.

3-й этап - поэтапное планирование учителем учебной деятельности, соответственно заданной цели.

4-й этап - отбор и изготовление учителем дидактических материалов для игровой деятельности. 5-й этап - комплектование групп. 6-й этап - формирование учебных задач.

7-й этап - выбор учащимся способов деятельности. Коллективное выдвижение гипотезы.

8-й этап - анализ и синтез собранных данных.

9-й этап - формирование выводов, заключений.

10-й этап - подведение итогов игры.

Применение дидактических игр обеспечивает:

- высокий уровень знаний учащихся,

- исчезновение неуверенности, скованности учащихся,

- желание идти на урок,

- интерес к предмету, формирование умений умственной самостоятельности учащихся.

Рассмотрим конкретные примеры игр, которые можно применить на уроках физики или использовать в качестве домашней работы.

\section{Snapshots of the Universe}

Snapshots of the Universe - удивительное приложение для iOS, выпущенное самим Стивеном Хокингом совместно с компанией Random House. Приложение состоит из восьми экспериментов, которые дают пользователям возможность не только получить базовые знания по физике, но и познакомиться с принципами, управляющими нашей Вселенной. В рамках предложенных экспериментов игроки могут отправлять ракеты в открытый космос, собирать собственные звёздные системы, искать и изучать чёрные дыры. Каждый эксперимент можно проводить бесчисленное количество раз, изменяя физические параметры и наблюдая за появляющимися эффектами. Чтобы лучше понять эксперименты, можно зайти в раздел объяснения результатов и посмотреть видео. Единственный минус данного приложения в том, что доступ платный.

\section{Particulars}

Это игра с уникальным сочетанием особенностей аркады и головоломки, место действия которых мир субатомных частиц. Взяв под контроль одного из кварков, игроки должны вести переговоры с фундаментальными силами Вселенной. Другие частицы будут притягиваться и отталкиваться, соединяться и изменять полярность, задача несчастного кварка - не терять контроль и избегать разрушения. Через всю игру красной нитью проходит история Элисон - молодого физика с нелёгким прошлым. Её путешествие через субатомный мир протекает в воспоминаниях и в конечном счёте приводит к удивительным открытиям. Есть бесплатная демо-версия, но полная игра так же является платной. 


\section{A Slower Speed of Light}

Игра от первого лица, разработанная лабораторией игр Массачусетского технологического института (MIT), даёт возможность игрокам познакомиться с восприятием пространства на околосветовых скоростях и понять теорию относительности. Задача игрока - перемещаться по 3D-пространству, собирать сферические объекты, которые замедляют скорость света на фиксированные значения, что даёт возможность наблюдать за различными визуальными эффектами эйнштейновской теории.

Чем медленнее движется излучение - тем яснее проступают некоторые физические эффекты. К 90-му собранному камню свет будет распространяться со скоростью пешехода, что заставит игроков почувствовать себя героями сюрреалистического мира. Среди явлений, с которыми может познакомиться герой во время игры, эффект Допплера (изменение при движении игрока длина волны регистрируемого им света, что приводит к изменению окраски видимых предметов, которая смещается в ультрафиолет и инфракрасную область), абберация света (увеличение яркости света в направлении движения), релятивистское замедление времени (различия между субъективным ощущением времени игрока и протекании времени во внешнем мире), преобразование Лоренца (искажение пространства на околосветовых скоростях) и т.д.

\section{Crayon Physics Deluxe}

Crayon Physics Deluxe - это 2D-пазл/игра «в песочнице», которая даёт возможность испытать игрокам, что было бы, если бы их рисунки могли превращаться в реальные физические объекты. Задача игрока - помогать шарику собирать звёздочки, рисуя подходящие для его движения поверхности - мосты, переправы, рычаги и т.д. Всё происходит в волшебном мире детского рисунка, где инструментами игрока являются восковые карандашики. Как минимум игра развивает художественное видение и творческие способности, как максимум - позволяет познакомиться с основами механики - гравитацией, ускорением и трением. Для теста на сайте представлена демо-версия, полная версия является платной.

\section{Algodoo}

Algodoo - это уникальная платформа 2D-моделирования физических экспериментов от Algoryx Simulation AB. C помощью мультяшных образов и интерактивных инструментов Algodoo позволяет создавать удивительные изобретения, разрабатывать игры для использования в классе или специальные эксперименты для лабораторных занятий по физике. В процессе своих естествоиспытаний и создания различных механизмов участники игры могут использовать жидкости, пружины, шарниры, двигатели, световые лучи, различные индикаторы, оптику и линзы. Моделируя различные конструкции и меняя параметры, игроки изучают трение, преломление, силу тяжести и т.д. Для новичков на сайте представлено подробное руководство, а также создан канал Youtube, на котором можно посмотреть десятки видео по теме.

\section{Video Physics}

Video Physics - приложение от Vernier Software \& Technology, которое позволяет вам делать анализ движения физических тел на основе видео. Всё что нужно от пользователя - загрузить видео, отметить кадр за кадром движущийся объект и настроить масштаб. После этого приложение с лёгкостью построит траекторию движения объекта и высчитает скорость его движения. С Video Physics можно высчитать скорость движения качели, американских горок, автомобиля, футбольного мяча - чего угодно, лишь бы изменялось положение объекта в пространстве.

\section{Sixty Symbols}

Ещё один сайт - Sixty Symbols посвящён символам, которые используются в физике. Создатели ресурса из Ноттингемского университета собрали 60 символов, обозначающих различные понятия, и в коротких, но очень занимательных и информативных видеороликах объяснили, что каждый из этих символов значит. Из этих выступлений можно узнать, почему у футбольного мяча «Джабулани» часто меняется траектория, в чём состоит секрет бразильского ореха, как постоянная Фейгенбаума помогает в понимании хаоса, или даже каким был характер Исаака Ньютона. Все понятия и явления учёные рассказывают в максимально доступной форме, используя подручные материалы.

В заключении хотелось бы отметить, что использование игровых технологий в преподавании физики помогают учителю активизировать познавательную деятельность учащихся и повысить интерес школьников к предмету. Благодаря использованию игровых технологий ученики понимают, что физика - это не только сложный теоретический материал, определения и формулы, но и простые опыты, демонстрации, которые понятны и доступны абсолютно всем.

Игра так же является довольно эффективным средством для обучения. Игра намного облегчает образовательный процесс, вовлекая в деятельность учащихся с разным темпом работы и уровнем владения материала. Она гарантирует позитивное эмоциональное состояние, повышает работоспособность, снимает усталость и увеличивает мотивацию к обучению. 
ЛИТЕРАТУРА

1. ВКР“Проектирование и разработка интерактивных учебных игр по физике с применением среды Unity 3D» / Д.М. Капись. - Перьм, 2018.

2. Мультиурок [Электронный ресурс]. URL: https://multiurok.ru/files/igrovaia-tekhnologiia-v-prepodavanii-fiziki.html / (дата 0бращения 09.01.2021).

3. Налегач А.Н. Дидактические игры в обучении физике // Физика: проблемы преподавания. - 2002. - № 3. - С. 54-58.

4. Хайруллина Я.А. Компьютерные игры в обучении физике в школе // NovaUm.Ru. - 2018. - №16. - c. 500-503.

5. Newtonew [Электронный ресурс]. URL: https://newtonew.com/app/13-igr-i-prilozhenij-dlja-izuchenija-fiziki /(дата обращения 09.01.2021).

6. Videouroki.net [Электронный ресурс]. URL: https://demo.videouroki.net/razrabotki/material-na-temu-didakticheskie-igry-v-obuchenii-fizike.html/ (дата o6ращения 09.01.2021).

○ Фадеева Елена Юрьевна (Lenoktggpy@mail.ru), Мингазов Рамиль Хаернасович,

Музафаров Азат Фаритович, Тухватуллина Лилия Азатовна.

Журнал «Современная наука: актуальные проблемы теории и практики»

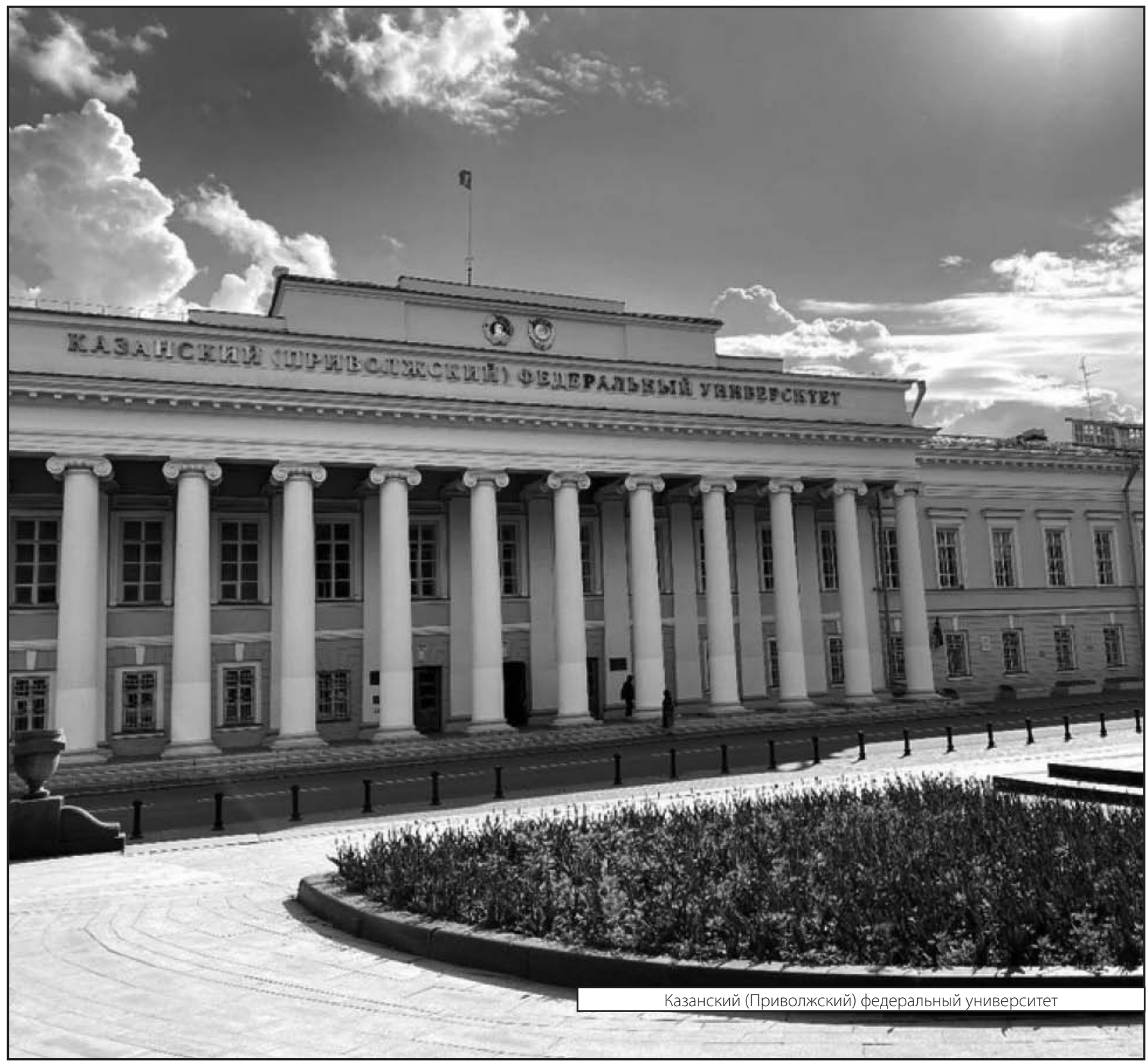

